\title{
Endovascular Treatment of Superior Cerebellar Artery Aneurysms
}

\author{
Vedat ACIK ${ }^{1}$, Ergun DAGLIOGLU², Ilkay AKMANGIT ${ }^{3}$, Fatih ALAGOZ ${ }^{2}$, Bige SAYIN ${ }^{3}$, Anil ARAT \\ ${ }^{1}$ Adana City Training and Research Hospital, Department of Neurosurgery, Adana, Turkey \\ ${ }^{2}$ Ankara Numune Training and Research Hospital, Department of Neurosurgery, Ankara, Turkey \\ ${ }^{3}$ Ankara Numune Training and Research Hospital, Department of Radiology, Ankara, Turkey \\ ${ }^{4}$ Hacettepe University School of Medicine, Department of Radiology, Ankara, Turkey
}

Corresponding author: Ergun DAGLIOGLU edaglioglu@gmail.com

\section{ABSTRACT}

AIM: To present our experience on superior cerebellar artery (SCA) aneurysms treated with embolization by using current endovascular techniques.

MATERIAL and METHODS: All SCA aneurysms treated by our endovascular team since 2013 were retrospectively evaluated. Clinical information and angiographic findings on presentation, during treatment and on follow-up were noted.

RESULTS: Endovascular treatment was the primary treatment method for SCA aneurysms during the study period. Twenty three patients ( 15 female, 8 male) with a mean age of 50.6 years, 12 of whom with subarachnoid hemorrhage were treated. Treatments included coiling (56\%), stent assisted coiling, stentriever assisted coiling, $Y$ stent assisted coiling and flow diversion with either flow diverter placement or telescopic stenting. Two patients died secondary to consequences of subarachnoid hemorrhage. The outcome of 1 patient was Modified Rankin Scale (mRS) 3 and the outcome of remaining 20 patients was mRS 0 . The rates of aneurysm occlusion according to Raymond-Roy classification were: class 1 in 11 patients, class 2 in 6 patients and class 3 in 2 patients on a mean follow-up of 15.3 months. Only one patient required retreatment.

CONCLUSION: Current endovascular techniques are able to address the high rate of recanalization and retreatment of SCA aneurysms which are currently the major drawbacks associated with primary coiling when compared with surgical treatment. It remains to be shown if use of these latest techniques are associated with increased risk of thromboembolic events.

KEYWORDS: Coil, Endovascular treatment, Flow diverter, Stent assisted coiling, Superior cerebellar artery aneurysm

\section{INTRODUCTION}

S uperior cerebellar artery (SCA) aneurysms are rare, accounting for $1 \%-2 \%$ of all intracranial aneurysms $(12,15)$. In general, SCA aneurysms have been evaluated within case series of posterior circulation aneurysms. Studies strictly focusing on SCA aneurysms are less common due to their low incidence (17). Surgery for posterior circulation aneurysms, including SCA aneurysms, is difficult because of narrow surgical field and proximity to the thalamoperforating arteries and cranial nerves. Alternatively, endovascular methods, which have been increasingly used in recent years with advanced technology and practice, have become the standard of care in many centres for the treatment of posterior circulation aneurysms.

\section{MATERIAL and METHODS}

Institutional case records of the cerebral aneurysms treated by our neurovascular team between January 2013 and June 2018 were analysed. Patients with endovascularly treated SCA aneurysms were identified and retrospectively evaluated. SCA aneurysm was defined as a saccular aneurysm arising strictly at the origin of the SCA. Midbasilar aneurysms
Vedat ACIK (D): 0000-0002-0371-5883

Ergun DAGLIOGLU (D) : 0000-0002-7162-3999
Ilkay AKMANGIT (1) : 0000-0002-6553-3639

Fatih ALAGOZ (D) : 0000-0001-6910-0585
Bige SAYIN (D) : 0000-0003-2824-5942

Anil ARAT (D) : 0000-0001-8386-4405 
extending superiorly to include the origin of the SCAs or large/giant basilar tip aneurysms involving the origins of SCAs and distal SCA aneurysms were excluded. Clinical and angiographic data were evaluated. Clinical information, including sex, age, Glascow Coma Score (GCS), and World Federation of Neurosurgery Score (WFNS) were collected. The angiographic variables included aneurysm location, aneurysm diameter, initial and follow-up occlusion status and endovascular treatment method employed. Clinical outcomes were evaluated based on the modified Rankin Scale (mRS). The Raymond-Roy classification (RR) was used to define angiographic outcome.

All the patients were treated by a single neurovascular team under general anaesthesia. Patients were preloaded with clopidogrel and acetyl salicylic acid (ASA), as described previously in the literature, unless they presented acutely after subarachnoid haemorrhage (14). Under systemic heparinisation, a triaxial catheter system was used to access the larger or straighter vertebral artery. If possible, primary coiling with or without balloon assistance was performed. In patients for whom coiling could not be performed, stents, stentrievers or flow diverters were used. During the later phase of the study period, tirofiban (loading dose of 10 microgram/ $\mathrm{kg}$ bolus and $0.15 \mathrm{microgram} / \mathrm{kg} / \mathrm{min}$ infusion for 24-36 hours) was administered to some patients based on the surgeon's preference. Heparinisation was discontinued at the end of the procedure. Patients were kept on dual anti-platelet treatment, evaluated clinically at 1 month and angiographically/ clinically at 4-6 months after the procedure. Clopidogrel was discontinued, and ASA was continued as a life-long therapy.

Patients were asked to visit for magnetic resonance angiography (MRA) at 3 months; for cerebral angiography (DSA) after 6 months; and annually for MRA.

\section{RESULTS}

A total of 23 patients (15 women and 8 men) were identified. Mean patient age was 50.6 (range: $20-78$ ) years. Seven of the aneurysms were on the right and 16 were on the left side. Endovascular treatment was the primary treatment method for SCA aneurysms during the study period. No patients with SCA aneurysms were referred for surgical treatment of their aneurysms. Thirteen patients had a single SCA aneurysm, whereas 10 had multiple aneurysms. In patients with multiple aneurysms, the SCA aneurysm was accompanied with basilar apex, P1 segment, middle cerebral artery (MCA) bifurcation, internal carotid artery (ICA), MCA M1 segment, posterior communicating artery, and V4 segment aneurysms. The mean diameter of the SCA aneurysms was $6.4 \mathrm{~mm}$ and ranged from 3 to $13 \mathrm{~mm}$.

Twelve patients presented with subarachnoid haemorrhage (SAH) (52\%). In these cases, the GCS was 15 in 3; 14 in 1; 13 in 2; 12 in 2; 8 in 1; 7 in 2 and 4 in 1 patient. The WFNS scores of these cases were 1 (4 patients), 2 (4 patients), 4 (3 patients) and 5 (1 patient). One patient with a preoperative GCS score of 7 and a WFNS score of 4 was discharged with a $\mathrm{mRS}$ score of 3 . The mRS score for the other 20 patients was 0 . Two patients died during the study period.
One patient developed an aneurysm rupture during coiling; however, bleeding ceased promptly with the continuation of coiling, and the patient was discharged without clinical sequel despite hydrocephalus and cranial nerve paresis at the postoperative period; these were managed without adverse consequences. One patient had a low clinical GCS score at admission, showed no clinical improvement after the intervention and subsequently died. In another patient, the neurological status worsened due to severe vasospasm after the procedure, and the patient died 1 week after the intervention. No ischaemic events were observed due to perforating artery injury during the postoperative period. During the postoperative follow-up, 1 patient developed a small occipital infarct 2 months after the procedure. The patient had inadvertently discontinued anti-aggregation the third day of treatment against our medical advice. This was associated with a minor visual field defect. This patient did not mention any clinical deficit and was leading a normal life as of the last clinical follow-up. Hydrocephalus developed in 2 patients presenting with $\mathrm{SAH}$; both patients were treated with ventriculostomy and ventriculoperitoneal shunt placement. Clinical and imaging features of the patients are summarized in Table I, case examples are given in Figures 1A, B; 2A-D; 3A-D.

Nineteen patients were followed-up angiographically for an average duration of 15.3 months. The acceptable occlusion rate (RR1 and RR2) was $89.4 \%$ (11 RR-1, 6 RR-2 and 2 RR-3 occlusions). One patient was treated with staged coiling followed by flow diversion. One patient underwent recanalisation of the aneurysm during follow-up (5\%).

\section{DISCUSSION}

In the present study, the clinical and radiological results of ruptured and unruptured SCA aneurysms that were treated with several endovascular methods were discussed.

Limited clinical data are available regarding the treatment of SCA aneurysms; few endovascular studies are reported in the literature. Further data on the endovascular treatment of SCA aneurysms is warranted, particularly because most of the existing data on SCA aneurysm treatment relates to either surgical or conventional endovascular treatment, disregarding the recent technical advances in the endovascular treatment of aneurysms $(7,11)$.

Endovascular treatment options for SCA aneurysms include primary coiling with or without a balloon, stent-assisted coiling (SAC), flow diverter (FD) placement and parent artery occlusion. Kim and colleagues reported on 53 patients with SCA aneurysms wherein 48 were treated with primary coiling and only 5 were treated with SAC. They reported a prevalence of $37.7 \%$ for RR-1 occlusion, $47.2 \%$ for RR-2 occlusion and $15.1 \%$ for residual aneurysms. There was no morbidity or mortality in this series (10). In another study by Peluso et al. that describes endovascular treatment of 34 SCA aneurysms; 4 aneurysms were treated with balloon assisted coiling, 1 with parent artery occlusion and 29 with primary coiling. They achieved $90 \%-100 \%$ occlusion rate in 32 patients 
and $80 \%$ in 2 patients. One patient who underwent balloon assisted coiling died due to a procedural perforation and another experienced ischaemia that resulted in morbidity (15). Among the 49 patients studied by Velioglu and colleagues, 47 underwent primary coiling, 2 with distal SCAs underwent parent artery occlusion with liquid embolic agents and died after the procedure. The GOS score of 42 patients was 5 , whereas that of the other 5 patients was 4 . Of the 40 patients who were followed up, 6 had aneurysm remnants and 34 had complete occlusion (19). Previous studies have reported a retreatment rate of $10 \%-25 \%$ for SCA aneurysms $(9,13,19)$.

In our cohort, the overall mortality was $10 \%$, whereas the procedure-related mortality and permanent morbidity were $0 \%$. On follow-up, a residual aneurysm was noted in $8 \%$ of the patients. This is consistent with the findings reported in previous reports on the surgical treatment of SCA aneurysms; Rodriguez-Hernandez et al. reported $7 \%$ residual aneurysm

Tablo I: Pre-Procedural Findings of the Patients, the Treatment Choices and Results of the Patients

\begin{tabular}{|c|c|c|c|c|c|c|c|c|c|c|}
\hline Patient & Age & Sex & $\begin{array}{l}\text { GCS } \\
\text { Score }\end{array}$ & $\begin{array}{l}\text { WFNS } \\
\text { Grade }\end{array}$ & $\begin{array}{l}\text { Aneurysm } \\
\text { side and } \\
\text { diameter }\end{array}$ & $\begin{array}{l}\text { Associated } \\
\text { aneurysm }\end{array}$ & Treatment & $\begin{array}{l}\text { Outcome } \\
\text { mRS }\end{array}$ & $\begin{array}{l}\text { Raymond } \\
\text { score }\end{array}$ & FU \\
\hline 1 & 67 & $\mathrm{~F}$ & 13 & 2 & $\mathrm{~L}, 3 \mathrm{~mm}$ & BA, Left PCA & SAC (Atlas*) & Exitus & - & Ext \\
\hline 2 & 51 & M & 7 & 4 & $\mathrm{R}, 13 \mathrm{~mm}$ & - & PC & 3 & 2 & $8 m$ \\
\hline 3 & 52 & $M$ & 13 & 2 & $\mathrm{R}, 3 \mathrm{~mm}$ & Right MCA & $\mathrm{PC}$ & 0 & 1 & $5 \mathrm{~m}$ \\
\hline 4 & 45 & $\mathrm{~F}$ & UB & UB & $\mathrm{R}, 5 \mathrm{~mm}$ & - & SAC (Atlas*) & 0 & 1 & $19 m$ \\
\hline 5 & 63 & M & 15 & 1 & $\mathrm{~L}, 4 \mathrm{~mm}$ & - & $\mathrm{PC}$ & 0 & 2 & $6 m$ \\
\hline 6 & 51 & $M$ & 14 & 1 & $\mathrm{R}, 6 \mathrm{~mm}$ & - & PC & 0 & $3 \mathrm{~A}$ & $22 m$ \\
\hline 7 & 53 & M & 7 & 4 & $\mathrm{R}, 5 \mathrm{~mm}$ & - & PC & Exitus & - & Ext \\
\hline 8 & 78 & $\mathrm{~F}$ & UB & UB & $\mathrm{L}, 10 \mathrm{~mm}$ & - & $\begin{array}{c}\text { Telescopic Stent } \\
\left(\text { Leo baby** }{ }^{*}+\text { Atlas }^{\star}\right)\end{array}$ & 0 & $3 A$ & $3 m$ \\
\hline 9 & 51 & $\mathrm{~F}$ & UB & UB & $\mathrm{L}, 4 \mathrm{~mm}$ & - & $\mathrm{PC}$ & 0 & 1 & $17 \mathrm{~m}$ \\
\hline 10 & 62 & $M$ & UB & UB & $\mathrm{L}, 5 \mathrm{~mm}$ & - & RSAC & 0 & 1 & $26 \mathrm{~m}$ \\
\hline 11 & 28 & M & 15 & 1 & $\mathrm{~L}, 5.5 \mathrm{~mm}$ & Left ICA & PC & 0 & 1 & $3 m$ \\
\hline 12 & 20 & $\mathrm{~F}$ & 15 & 1 & $\mathrm{~L}, 13 \mathrm{~mm}$ & - & $\begin{array}{c}\text { PC+RSAC+FD+stent } \\
\left(\text { Silk }^{\star \star *}+\text { Leo baby }{ }^{\star *}\right)\end{array}$ & 0 & 2 & $9 m$ \\
\hline 13 & 62 & $\mathrm{~F}$ & 4 & 5 & $\mathrm{R}, 4 \mathrm{~mm}$ & Bilat ICA, BA & PC & 0 & 1 & $24 m$ \\
\hline 14 & 30 & M & UB & UB & $\mathrm{R}, 3 \mathrm{~mm}$ & Bilat P1 & SAC (Atlas*) & 0 & 1 & $7 \mathrm{~m}$ \\
\hline 15 & 51 & $\mathrm{~F}$ & UB & UB & $\mathrm{L}, 3 \mathrm{~mm}$ & Left PCoM & FD $\left(\right.$ Silk $\left.^{\star \star \star}\right)$ & 0 & 1 & $17 \mathrm{~m}$ \\
\hline 16 & 51 & $\mathrm{~F}$ & UB & UB & $\mathrm{L}, 8 \mathrm{~mm}$ & Left M1, ICA & SAC (Leo baby $\left.{ }^{\star \star}\right)$ & 0 & 2 & $28 m$ \\
\hline 17 & 50 & $\mathrm{~F}$ & UB & UB & $\mathrm{L}, 4 \mathrm{~mm}$ & $\begin{array}{l}\text { Right MCA, } \\
\text { ICA }\end{array}$ & $\begin{array}{l}\text { SAC (initial trial of } \\
\text { RSAC) (Leo baby*) }\end{array}$ & 0 & 1 & $6 m$ \\
\hline 18 & 25 & $\mathrm{~F}$ & UB & UB & $\mathrm{L}, 7 \mathrm{~mm}$ & - & PC & 0 & 2 & $33 m$ \\
\hline 19 & 64 & $\mathrm{~F}$ & UB & UB & L, 9 mm & - & PC & 0 & 1 & $45 \mathrm{~m}$ \\
\hline 20 & 42 & $\mathrm{~F}$ & 12 & 2 & $\mathrm{~L}, 9 \mathrm{~mm}$ & - & $\mathrm{PC}$ & 0 & - & N/A \\
\hline 21 & 62 & $\mathrm{~F}$ & UB & UB & $\mathrm{L}, 11 \mathrm{~mm}$ & - & Ystent+coil (Atlas*) & 0 & 1 & $10 \mathrm{~m}$ \\
\hline 22 & 64 & $\mathrm{~F}$ & 12 & 2 & $\mathrm{~L}, 5 \mathrm{~mm}$ & Left ICA & $\mathrm{PC}$ & 0 & - & N/A \\
\hline 23 & 42 & $\mathrm{~F}$ & 8 & 4 & $\mathrm{~L}, 9 \mathrm{~mm}$ & $\begin{array}{l}\text { Right ICA, } \\
\text { Bilat V4 }\end{array}$ & PC & 0 & 2 & $3 m$ \\
\hline
\end{tabular}

Abbreviations: SAC: Stent asisted coiling, RSAC: Retriever stent asisted coil, FD: Flow diverter, UB: Unbleed, BA: Basilar artery, ICA: Internal carotid artery, PCA: Posterior cerebral artery, MCA: Middle cerebral artery, PCoM: Posterior communicating artery, F: Female, M: Male, PC: Primary coilling, R: Right, L: Left, N/A: Not avaliable, m: months.

*Stryker Neurovascular, Fremont, USA; **Balt Extrusion, Montmorency, France; ***Balt Extrusion, Montmorency, France. 

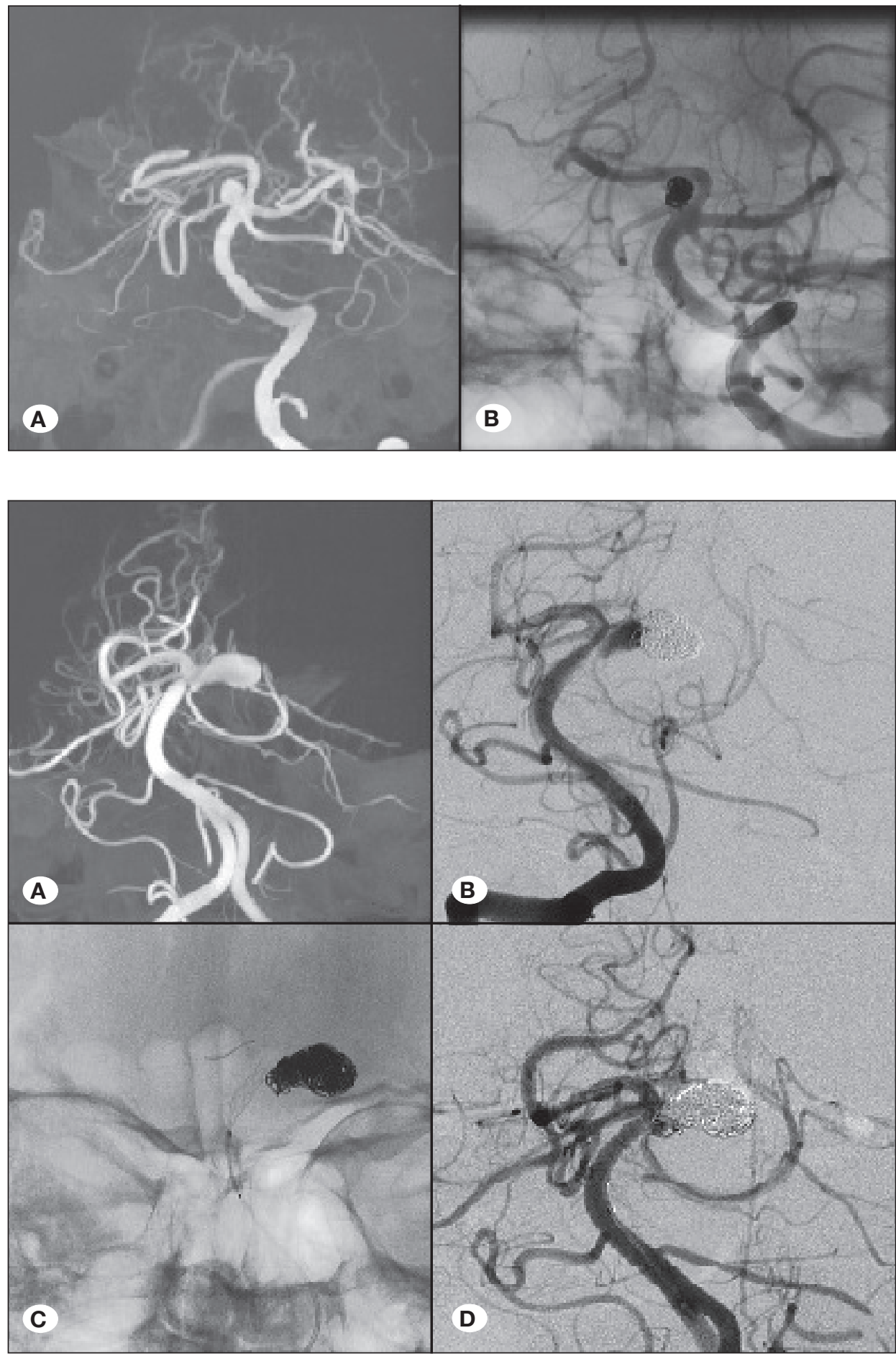

Figure 1: Three dimensional (3D) image of the right superior cerebellar artery aneurysm reconstructed from DSA (A) (Patient 4). Aneurysm was treated with stent assisted coiling using the new generation Neuroform Atlas stent (B).
Figure 2: Three dimensional (3D) image of the left superior cerebellar artery aneurysm reconstructed from DSA (A) (Patient 12) which was treated with primary coiling at the initial session (B). Residual aneurysm was treated with a flow diverter and conventional stent deployment (C). Postoperative AP digital subtraction image demonstrated occlusion of the aneurysm (D). rate, whereas Patra et al. found $11 \%$ residual aneurysms $(13,16)$. In terms of safety, our results are similar to the endovascular series mentioned above and to the surgical series reported by experienced surgeons. For example, Rodríguez-Hernández et al. operated on 63 patients with SCA aneurysms and reported $4.8 \%$ mortality and permanent morbidity (16). However, with a $5 \%$ rate noted for mid-term recanalisations, our study showed better treatment durability than the former endovascular series. In fact, the results are comparable with the surgical results. The most likely reason for this outcome is the use of stents and FDs in our series.

The rate of retreatment in the cases with stented aneurysms that were followed up was $0 \%$, and the rate of angiographically stable, small aneurysm neck remnants in SAC was $20 \%$. This was expected, considering the low rate of embolisation 


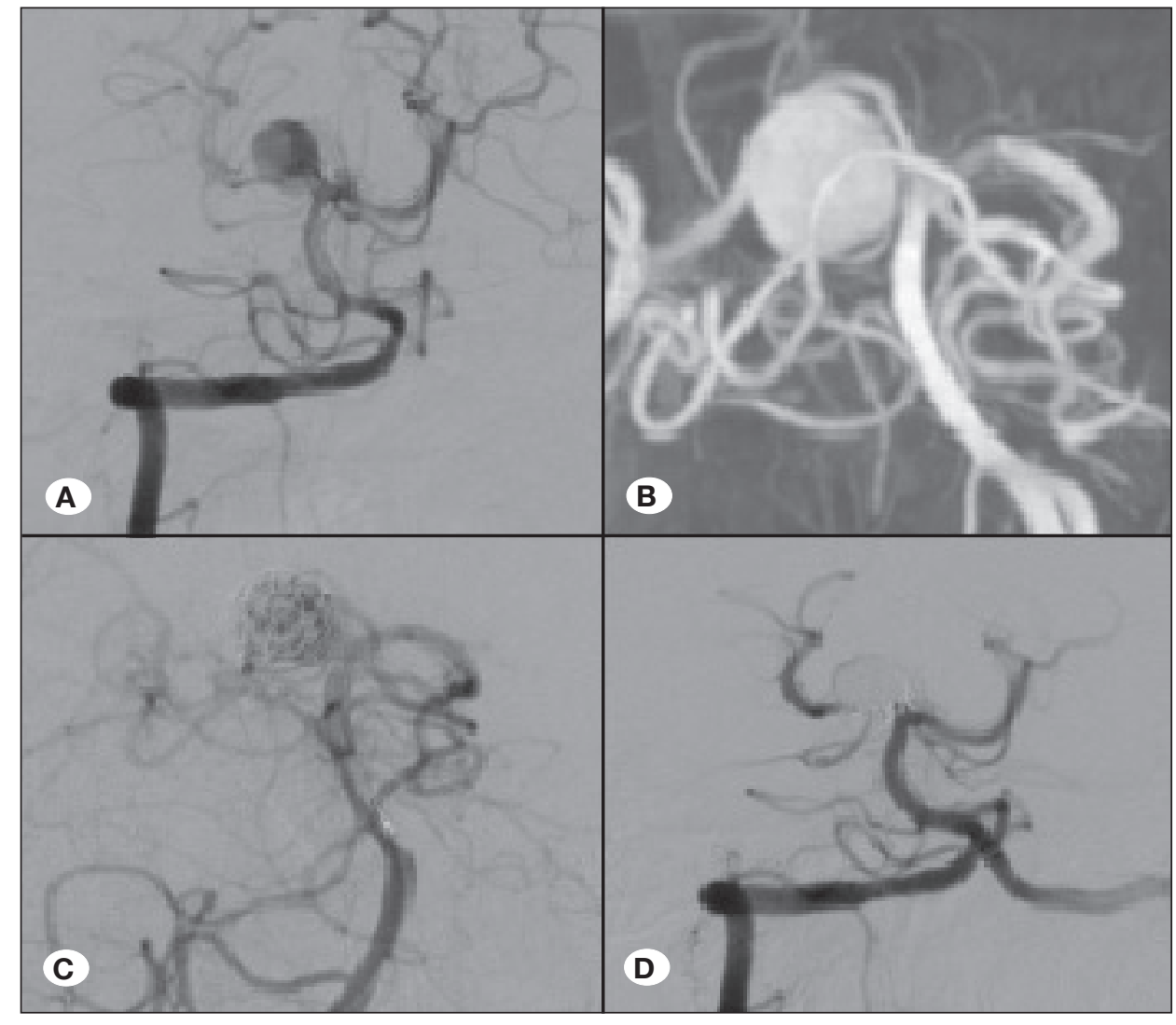

Figure 3: Preoperative anteroposterior DSA (A) (Patient 2), and three dimensional (3D) reconstructed image (B) show a right superior cerebellar artery aneurysm. Perioperative (C), and postoperative anteroposterior (D) DSA image show completely occluded aneurysm after primary coiling. of recurrent aneurysms with the latest generation of mini intracranial stents in distal bifurcation aneurysms $(1,3,5)$. Moreover, the rate of obliteration for the 3 aneurysms managed using flow diversion (1 with telescopic stenting and 2 with FDs) is also concordant with the lower rates of total occlusion following flow diversion for bifurcation aneurysms (18). Flow diversion was performed only for aneurysms considered to be poor candidates for optimal coiling because of a higher risk of residual aneurysms, slightly increasing the overall risk of residual aneurysms. However, this resulted in a higher success rate because it enabled endovascular treatment of SCA aneurysms in this unselected group of SCA aneurysms.

Several reports have described the endovascular treatment of SCA aneurysms using the new generation intracranial mini stents within the context of endovascular treatment of all intracranial aneurysms without specifically referring to the challenges faced in the treatment of SCA aneurysms $(2,18,21)$. Moreover, a recent meta-analysis on flow diversion in all intracranial aneurysms mentions that only about 7 SCA aneurysms were treated using this method (20). There are only 2 detailed descriptions in the literature about flow diversion for saccular SCA aneurysms $(4,8)$. Finally, to our knowledge, there are no reports on the treatment of these aneurysms with dual SAC using new generation intracranial stents or on the use of stentriever-assisted coiling in the literature. Thus, we believe that this is the only report on the endovascular treatment of SCA aneurysms with a comprehensive coverage of the currently available endovascular techniques.
SCA aneurysms are similar to middle cerebral aneurysms in many ways. Both are located in perforator-rich areas and commonly present with a tortuous and small side branch. The use of FDs as the primary treatment for these aneurysms appears challenging due to rich perforators of the basilar artery and proximity to the SCA origin. The difficulties that are commonly encountered in the endovascular treatment of middle cerebral aneurysms are expected to occur in the treatment of SCA aneurysms as well $(6,18)$. We believe that adopting the latest endovascular techniques for the treatment of SCA aneurysms will increase the success rate of endovascular treatment in the immediate post-procedure period and in the long term. However, this involves both, advantages and disadvantages. It appears that in a non-selected population of SCA aneurysms, the utilisation of endovascular methods yields angiographic results similar to those of surgery. Though it is not the major aim of the present study, a potential exists for thromboembolic events periprocedurally for almost every endovascular treatment or during follow-up due to the use of permanent intra-arterial scaffolds.

\section{CONCLUSION}

We present a unique series of SCA aneurysms treated using the latest endovascular techniques. Lower rates of aneurysm occlusion and risk of recanalisation for SCA aneurysms were noted with the use of endovascular methods for SCA aneurysms. It remains to be determined whether the use of these newer techniques is associated with an increased risk of thromboembolic events. 


\section{REFERENCES}

1. Akmangit I, Aydin K, Sencer S, Topcuoglu OM, Topcuoglu ED, Daglioglu E, Barburoglu M, Arat A: Dual stenting using low-profile LEO baby stents for the endovascular management of challenging intracranial aneurysms. American J Neuroradiology 36:323-329,2015

2. Alghamdi F, Mine B, Morais R, Scillia P, Lubicz B: Stentassisted coiling of intracranial aneurysms located on small vessels: Midterm results with the LVIS Junior stent in 40 patients with 43 aneurysms. Neuroradiology 58:665-671, 2016

3. Aydin K, Arat A, Sencer S, Barburoglu M, Men S: Stentassisted coiling of wide-neck intracranial aneurysms using low-profile LEO baby stents: Initial and midterm results. American J Neuroradiology 36:1934-1941,2015

4. Briganti F, Leone G, Cirillo L, de Divitiis O, Solari D, Cappabianca P: Postprocedural, midterm, and long-term results of cerebral aneurysms treated with flow-diverter devices: 7-year experience at a single center. Neurosurgical Focus 42(6):E3,2017

5. Cay F, Peker A, Arat A: Stent-assisted coiling of cerebral aneurysms with the Neuroform Atlas stent. Interventional Neuroradiology 24:263-269,2018

6. Feng Z, Li Q, Zhao R, Zhang P, Chen L, Xu Y, Hong B, Zhao W, Liu J, Huang Q: Endovascular treatment of middle cerebral artery aneurysm with the LVIS junior stent. J Stroke Cerebrovascular Disease 24:1357-1362,2015

7. Greving JP, Wermer MJ, Brown RD, Morita A, Juvela S, Yonekura M, Ishibashi T, Torner JC, Nakayama T, Rinkel GJ, Algra A: Development of the PHASES score for prediction of risk of rupture of intracranial aneurysms: A pooled analysis of six prospective cohort studies. Lancet Neurology 13:59-66, 2014

8. Guedon A, Clarencon F, Di Maria F, Rosso C, Biondi A, Gabrieli J, Rojas P, Chiras J, Sourour N: Very late ischemic complications in flow-diverter stents: A retrospective analysis of a single-center series. J Neurosurgery 125:929-935, 2016

9. Jin SC, Park ES, Kwon DH, Ahn JS, Kwun BD, Kim CJ, Choi CG: Endovascular and microsurgical treatment of superior cerebellar artery aneurysms. J Cerebrovasc Endovasc Neurosurg 14:29-36, 2012

10. Kim CH, Cho YD, Jung SC, Ahn JH, Kang HS, Kim JE, Cho WS, Han MH: Endovascular treatment for superior cerebellar artery aneurysms: Morphological features, technique, and outcome. Neuroradiology 56:647-654, 2014
11. Morita A, Kirino T, Hashi K, Aoki N, Fukuhara S, Hashimoto N, Nakayama T, Sakai M, Teramoto A, Tominari S, Yoshimoto $\mathrm{T}$ : The natural course of unruptured cerebral aneurysms in a Japanese cohort. N Engl J Med 366:2474-2482, 2012

12. Pandey AS, Koebbe C, Rosenwasser RH, Veznedaroglu E: Endovascular coil embolization of ruptured and unruptured posterior circulation aneurysms: Review of a 10-year experience. Neurosurgery 60:626-636, 2007

13. Patra DP, Bir SC, Maiti TK, Kalakoti P, Cuellar-Saenz HH, Guthikonda B, Sun H, Nanda A: Superior cerebellar artery aneurysms, the "Sui Generis" in posterior circulation: The role of microsurgery in the endovascular era. World Neurosurgery 94: 229-238, 2016

14. Peker A, Akgul E, Daglioglu E, Akmangit I, Kaya T, Belen D, Arat $A$ : Tapered flow diverters in the treatment of intracranial aneurysms. Turk Neurosurgery 27:863-866,2017

15. Peluso JP, van Rooij WJ, Sluzewski M, Beute GN: Superior cerebellar artery aneurysms: Incidence, clinical presentation and midterm outcome of endovascular treatment. Neuroradiology 49:747-751, 2007

16. Rodríguez-Hernández A, Walcott BP, Birk H, Lawton MT: The superior cerebellar artery aneurysm: A posterior circulation aneurysm with favorable microsurgical outcomes. Neurosurgery 80:908-916, 2017

17. Saeki N, Rhoton AL Jr: Microsurgical anatomy of the upper basilar artery and the posterior circle of Willis. J Neurosurgery 46:563-567, 1977

18. Topcuoglu OM, Akgul E, Daglioglu E, Topcuoglu ED, Peker A, Akmangit I, Belen D, Arat A: Flow diversion in middle cerebral artery aneurysms: Is it really an all-purpose treatment? World Neurosurgery 87:317-327, 2016

19. Velioglu M, Selcuk H, Kizilkilic O, Basekim C, Kocer N, Islak C: Endovascular management of superior cerebellar artery aneurysms: Mid and long-term results. Turkish Neurosurgery 25:526-531, 2015

20. Wang CB, Shi WW, Zhang GX, Lu HC, Ma J: Flow diverter treatment of posterior circulation aneurysms. A meta-analysis Neuroradiology 58:391-400,2016

21. Wang J, Vargas J, Spiotta A, Chaudry I, Turner RD, Lena J, Turk A: Stent-assisted coiling of cerebral aneurysms: A singlecenter clinical and angiographic analysis. J Neurointerv Surg 10:687-692,2018 